\title{
A New Creative Culture Example: The Case of the 'What will be Happen News Bulletin' in North Cyprus
}

\section{Dilan Ciftci}

Assist. Prof. Dr., Department of Journalism, Near East University, Near East Boulevard, Nicosia TRNC

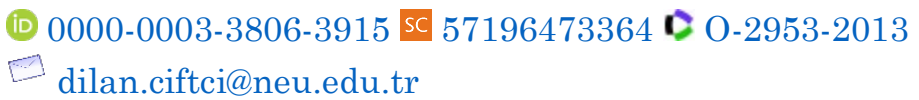

\section{Fuat Bogac Evren}

Res.Assist., Department of Visual Communication and Design, Near East University, Near East Boulevard, Nicosia - TRNC

$\square$ fuat.evren@neu.edu.tr

\begin{abstract}
ARTICLE INFO
Received: 20 September 2018

Accepted: 27 October 2018

Published: 12 November 2018

DOI: https://doi.org/10.12973/ojemt/3959

ABSTRACT

The aim of the current study is to explore the conceptual development of trolling behavior and creative culture on new media in the North Cyprus especially on the 2015 Presidential Election. Cyprus presents a unique opportunity for the investigation of creative language and related issues due to its vibrant and unevolved media systems. Currently, there is no comprehensive study that incorporates the conceptual development of trolling culture in North Cyprus political communication in general. This study is also significant for application of the trolling culture in North Cyprus political communication as an election campaign strategy during the horse-race periods. In total, 23 videos were coded according to codebook with regard to creative language and the characteristics of trolling behavior. In order to provide a conceptual definition of the meaning of troll culture for Turkish Cypriots small survey was conducted by 100 Cypriots. The present data suggests that What Will Be Happen News Bulletin 2015 Presidential Election videos in YouTube channel demonstrated higher creative culture examples, which represent classical trolling behavior. The analysis of small survey and content-analysis suggest that the Mehmet Ekin Vaiz was unique due to being the first application of Turkish Cypriot political communication is adopting a classical trolling behavior in 2015 Presidential Election.
\end{abstract}

Keywords: trolling, creative culture, social media, political communication, new media, mobile behavior

\section{INTRODUCTION}

Since the beginning of the $21^{\text {st }}$ century, different forms of communication techniques on the internet have created the basis for the emergence of new forms of communication with the need for the added qualities of the mobile communication, such as digitality, interactivity, multimedia formality, hypertextuality, diffusion and virtuality (Binark \& Löker, 2011; Park, 2017; Silverstone, 1999; Straubhaar, et al., 2011; Ziani, et al., 2018). Although each of these attributes has different meanings and offers innovations to its users, the basic partnership of all of them is to enable user-based content production. In 
particular, by switching from Web 1.0 to Web 2.0 technology, users are not only accepted as the consumer of information but also they are actively engaged in the producing process.

Meikle's (2016) points out that social networks (Facebook, Twitter, Instagram etc.) are used for multidimensional purposes. Therefore, it is true to mention that these social networks are both inter-personal and public communication tools. Here, it is vital to add that social networks are becoming most effective political communication tools as well. Also, Meikle (2016) criticizes that social networks since these social networks are used to make all personal information transparent. Nowadays, we are confronted with the fact that with non-professional creativity-based content media production and sharing. Therefore, these shares create new business opportunities for who are interested with creativity practices on social networks (Meikle, 2016, p. 17). Thus, these new trends in social media sharing has started to be used by different social network users profiles', which lately creates the new phenomena of creative culture known as 'trolling'.

In this study, the case of the 'What Will Be News Bulletin' of Mehmet Ekin Vaiz has examined as a first example of the practicing creative culture among social networks in North Cyprus. The case of 'What Will Be News Bulletin' has chosen since Mehmet Ekin Vaiz has used the creative language practices under the name of tolling and it is the first application of the trolling culture into North Cyprus political communication by reporting the North Cyprus 2015 Presidential Election issues. In this sense, this study significantly based on the two rounds of 2015 Presidential Election of North Cyprus, which first round had been held on $19^{\text {th }}$ of April and the second round had been held on $26^{\text {th }}$ of April 2015. In the light of this information, the 23 videos of 2015 Presidential Election that are published in Mehmet Ekin Vaiz's social network accounts under the name of 'What Will Be Happen News Bulletin' (Facebook and YouTube) used to elaborate creative language practices and the application of the trolling culture in North Cyprus political communication.

The aim of the study is to reveal what kind of a trolling practices are available in the application of trolling culture in North Cyprus political communication. Therefore, 'What Will Be Happen News Bulletin' is undertaking in order to investigate whether the publications have taken a critical and dissident view of the North Cyprus 2015 Presidential Election with addressing the creative language practices that are fed from humor. In this way, it has examined whether the trolling culture, accepted as a product of creative culture, has developed a critical approach to current political situations. For this purpose, the videos are evaluated by using the content-analysis technic based on the structured codebook. There is one main research question that this study seeks to answer, which is: Did Mehmet Ekin Vaiz's 'What Will Be Happen News Bulletin' practice an application of 'trolling culture in political communication' during the North Cyprus 2015 Presidential Election?

\section{LITERATURE REVIEW AND RESEARCH QUESTION}

Trolls and Trolling Behaviors as a Creative Culture Product

Bishop (2014) describes the new social network jargon of troll as a technique of deceiving the enemies that has been used by US Army's soldiers in 1960s. Similarly, Taiwo (2014) defines trolling as a conscious act of provocation of collective event of certain societies. On the other hand, according to Coleman (2012, p. 110) the aim of trolling behaviors is to provide harmful and inaccurate information of not only persons but also 
institutions, which she supports that in this way trolls destroy persons' and institutions' public reputations.

Moreover, Coleman (2012) emphasizes that trolls are often hide their identity in order to attack these persons and institutions. As they are hidden their identity behind the masks, Ozsoy (2015) criticizes trolls as assessing the abusive, sexist, discriminatory, racists and destructive discourse in the social networks. By accepting the trolls as a way of thinking internet subculture tragedy, it is often deceiving and manipulating other users by hiding their identity by subjecting them to false and biased information, or sharing their thoughts in order to criticize social problems by a critical point of view. In the light of this information, troll accounts could be accepted as a personal brand creation which is benefited from the social networks.

Furthermore, Goffman (2014) explains that trolls present themselves as an artist who has exhibition of themselves on the stage. Moreover, Bishop (2014) emphasizes two opposing trolling behavior categories, which are classical trolling (for entertainment purposes) and anonymous trolling (for provocative purposes). To begin with the classical trolling, it is true to say that while classical trolls aim to communicate with other people through social networks, anonymous trolls aim to destroy the communication and relationships between the social networks users.

At this point, when we look at both opposing categories of trolling behaviors especially in North Cyprus, it is observed that in Turkish Cypriot society the classical trolling examples are much more than the anonymous trolling ones. As Karatas and Binark, (2016, p. 434) point out that the troll accounts in social networks try to establish a link between creative culture and creative language mostly as a means of entertainment purposes. In this sense, trolls offer significant contributions to creative culture through language and discourses that they have distributed through social networks. Thus, the most prominent feature of the trolls is the use of creative language, which has the distinct method in order to enhance more attractive and popular sharing by using visual imaginary. To define trolls in social networks differently, it is also possible to say that trolling: is used to increase the number of followers by creative language practices and convert them into an interested people by attracting their attention mostly in the social networks.

On the other hand, Hardaker (2013) argues that unlike Bishop and Coleman's approaches to trolling, trolls consciously exhibit oppositional or aggressive behavior. Here, Hardaker compromises that trolls are often apply aggressive communication and language practices. Hardaker also draws attention to their opposing direction too. At this point, Taiwo (2014) unlike Bishop divides trolling practices into two different categories. First, trolls serve as a platform to debate social issues through making them visible. Second, trolls use to subject social debates to find their deficits and disgrace for certain social networks followers.

This contrasting situations between two different categories of trolls often represent the actual appearance of political camouflages and social polarization on the Internet. In this study, trolling behaviors were dealt with the use of purely creative language practices by criticizing social problems from an opposing point of view, or by publicizing social networking issues that are not visible on the public sphere. Apart from this type of trolling behavior, there are also trolls which systematically provide hate speech as mentioned above which humiliate persons and institutions by cyberbullying. In the light of these facts, trolling practices are thought to be valuable in terms of their creative language 
practices based on humor which is the alternative way of questioning the current politicalsocial order and power over social networks in the form of classical trolling application.

To this extent, trolling practices through Twitter usage in Turkey, trolls and their creative direction are accepted as a comprehensive area for academic studies by drawing attention to the direction of distributing communicative action (Binark et al., 2015, p. 128). Moreover, Binark (2015) refers to his interview with Emek Cayli Rahte that trolls presented on Twitter sometimes produce aggressive content by insulting or lynching in order to criticize social issues by using creative language for issues that relate the current agenda (Binark et al., 2015, p. 128). Here, it is urgent to highlight that there are also creative language use and vocabulary, as the discursive practices of trolls include humiliating, sexist, discriminatory, profanity and insulting content. Yet, it should be noted that a significant portion of the content in which the use of humor-based creative language is dominated are swearing and male-dominated sexist language. However, humor-based oppositional approaches are created by word games are supported by the users' images', called caps (memes). Thus the use of creative language with shared visibility extents a hyper-textual level (Binark et al., 2015, p. 142).

When we examine the Turkey and North Cyprus entertainment content generating troll, their discourses' are systematically targeted a person or institutions with a critical approach. These efforts make a social issue on the agenda visible by naturalizing it with the help of the humor-based discussion. For example, the former president of Ankara Municipality Melih Gökçek has been criticized by some of troll accounts for sharing his photos in front of the tank [because the date was 15 July 2016, where there was a coup attempt in Turkey] by saying 'This is better... I want to know you and see you...' (Please see Figure 1).

As Figure 1 illustrates, troll accounts share a textual expression of him with the caps and present a humor-based critical approach to his political expressions and sharing. Therefore, the opposing attitude towards Gökçek made him more visible and remarkable by these caps prepared by the troll accounts. In other words, it is crucial to discuss the power of caps that they become an important tool in communicating power not only for ruling parties but also for opposing parties at the same time in certain societies. Significantly, caps are successful in attracting the attention of interest among social networks users who have encountered thousands of messages and visual text during the day (Aktas, 2016).

Beyond just being a product of humor, trolls can be regarded as an important means of mass communication because of its convincing and destructive nature. The study entitled by 'A New Creative Culture Example: The Case of the 'What Will Be Happen News Bulletin' in North Cyprus' emphasizes that Twitter users circulation in Turkey accept caps as a creative culture products, in contrast to the negative perception that the mainstream media make the news publicly critical (Karatas \& Binark, 2016, p. 445). In other words, the content produced by the trolls can provide any kind of corruption in the political arena, and the absurdity in the different cultural context in order to enable the other users' awareness and to question the common social negativities (Karatas \& Binark, 2016, p. 446). Corruption and problems in the political and cultural contexts in a humorous way with the contribution of creative language can also cause these awareness problems concerning the political and cultural field in the society. Moreover, there is also another important problem of the anonymous discriminatory sharing of insults and swearing which cannot be ignored as well. In order to stop these kind problems, it is 
İbrahim Melih Gökçek
@06melihgokcek

BU NE CESARETTIIR YARABBI...SENI TANIMAK ISTIYORUM, YIĞIDIM...BENI MUTLAKA ARA...
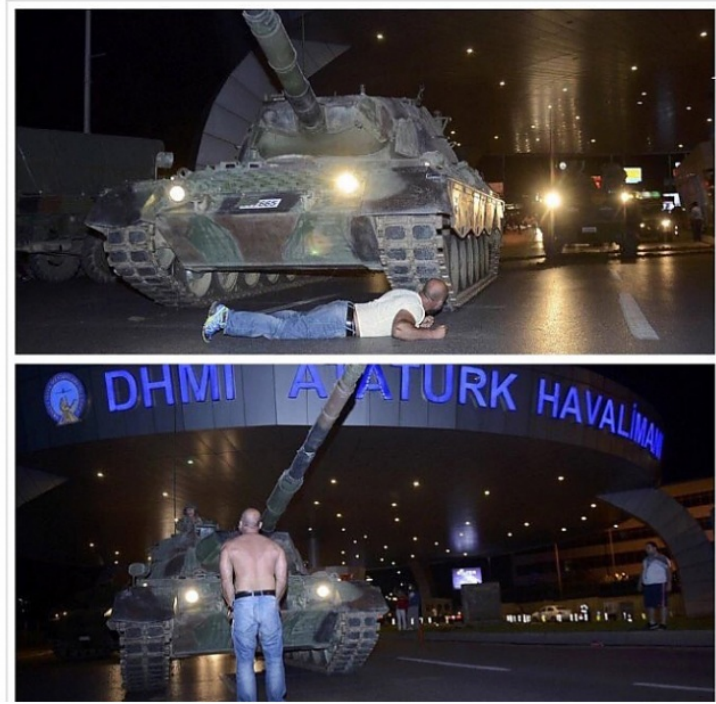

Captain $\mathrm{K}^{2}$

Thoraykorkmaz

Falipediliyor

BU NE CESARETTIR YARABBI...SENI TANIMAK ISTIYORUM, YIĞIDIM...BENI MUTLAKA ARA...

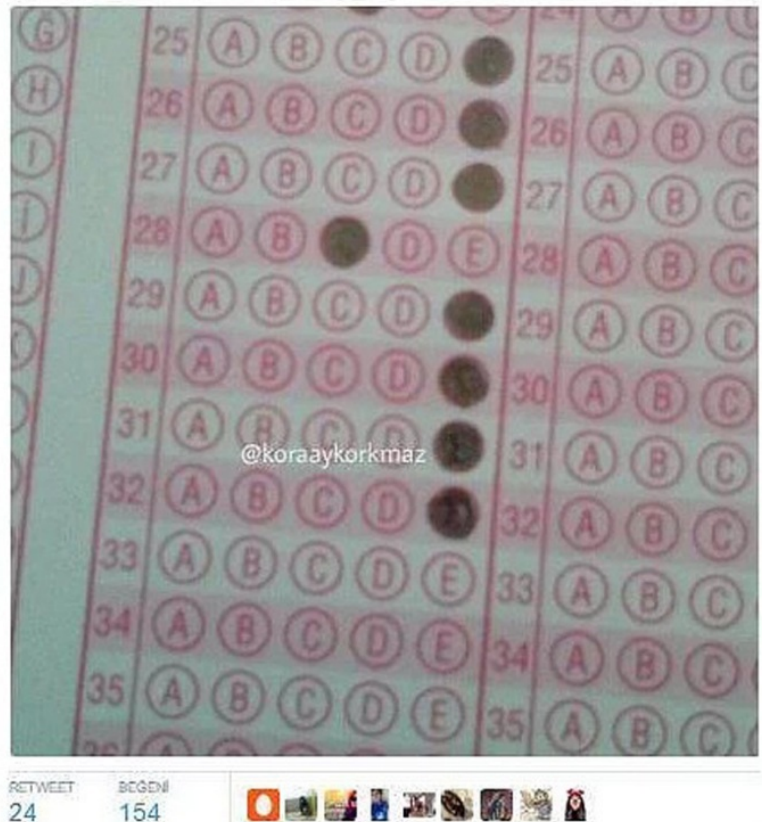

Figure 1. Trolling Examples of Melih Gökçek by a Twitter User in Turkey

necessary to make some responses instead of ignoring these shares (Binark et al., 2015, p. 155).

The New Phenomena: New Media and Mobile Communication

Significantly, Kim et al. (2016) argue that the mobile communication industry scale has grown last twenty years when Apple built the mobile ecosystem where the competition with the devices has been started. According to Chen et al. (2016) when new communication technologies are mentioned, such as personal computers, digital games, internet, mobile phones, and electronic tablets and similar technical devices, we have witnessed unprecedented advances in modern information from the evaluation of the personal computers that communication devices were eventually converging (Chang \& Chen, 2005; Goncharova, 2012; Halder, et al., 2015; Suh, Lee, \& Park, 2012; Tossell, et al., 2012).

On the other hand, as Ozok and Wei (2010) found empirical evidence on consumer usability preferences in online shopping using stationary and mobile devices among college students population was an urgent example that the introduction of Web-enabled mobile devices allowed customers to do electronic shopping without being limited to a desktop computer and a hard-wired Internet connections. The most striking element in the concept of new communication technologies is being the 'new'. Personal computers, which are among the new communication technologies, should be considered separately because of their features. Since, personal computers have high processing power, memory and communication ability, it has more autonomy compared to other means of communication devices, such as telephone, newspapers and etc. In addition to that, it is true to say that computer technology creates the technological basis of digital communication tools with regards to quantitative advantages offered by the new media. 
Rogers (1995) mentions that massive interactive ability of new media. Moreover, interactions in new media environments are different from traditional media interactions. It is generally assumed that there is a one-way communication in traditional media environments, however, this approach is not entirely correct, since interactions in traditional media environments is achieved through a number of feedback channels (Geray, 2003, p. 18). With the mass-unification feature, the user can share content with one person or with millions of people at the same time (Geray, 2003, p. 18-19). Critically, Martin (2016, p. 26) express that "For citizens in many countries, mobile media have become increasingly popular and important outlets for political communication, including exchanges through social networking sites, political news consumption, texting social contacts about politics, and mobilizing political protests..."

It is not necessary for the user to be able to access a message sent to him at the same time, either in the place where the message is sent or at the place where the message is reached (Ozinanir, 2009, p. 12). According to Silverstone (1999), new media environments have features such as digital convergence, many-to-many communication, virtuality, interactivity, and globalization. Interactions and globalist issues are also present in different forms of communication before new media environments have been emerged. On the other hand, Torenli (2005, p. 94-96) mentions that the capabilities of the new communication technologies mentioned above increase the performance and networking capabilities of the systems, as the costs increases and performance improves, as technological integration accelerates, portability becomes widespread, ease of use becomes easier.

Although new communications technologies have important and advantageous qualities such as widespread portability, speed of technological integration, cost reduction and ease of use, most of the world still does not have access to new communication technologies. According to the results of the research conducted in 2016 in order to measure the rate of internet use worldwide, the internet usage rate is limited to 3.4 billion people (Ayvaz, 2016). This conclusion proves the problems people have in accessing the new communication technologies mentioned above. In addition, opportunities to access new communication technologies show a decreasing tendency from developed capitalist countries to less developed countries (Ozinanir, 2009, p. 13).

\section{More from a Social Network: YouTube}

Although YouTube is known as the first video sharing network, it is thought that shareyourworld.com, which was originally launched in 1997, is the first video sharing network. The site of shareyourworld.com which allows users to upload and share videos like YouTube, did not survive because of the lack of internet speed of the time (Woog, 2008, p. 9). PayPal had been established in November 2005 by three former employees were Jawed Karim, Chad Hurley and Steve Chen, was a network-based banking system, YouTube attracted Google's attention due to its short-term intense interest and was purchased by Google in 2006 (Lister, et al., 2009, p. 225).

YouTube serves as a multi-dimensional internet platform when compared to other social networks; such as publishing platform, media archive, and social network. YouTube's social networking differs from popular social networks like Facebook and Twitter by allowing users to upload and share videos and other users to like, comment on, and follow. Thus user-to-user interpretations allow users to interact with each other. With Google's purchase of YouTube, all Google accounts have become available for YouTube starting in 2012. As all Google users are also YouTube users at the same time, YouTube's 
number of registered users has increased and the number of video contents on the site have been also enlarged.

With the increasing use of mobile internet, YouTube has become a commercial and political space rather than just uploading a self-video and videos from others. Users earn money based on the number of impressions, and they have benefited from the ads they receive in the original video content that they publish. Today, there are thousands of users who became YouTube phenomena everywhere in the world, and they earn from their YouTube ads. The vast majority of these people who become phenomena are also recognized by video blogs (abbreviated as Vblog), which are called online video diaries.

The concept of Vblogger is also used to describe people who have video blogs. When we look at YouTube's political landscape, it is known that various users have been circulating YouTube through critically, aggressively, and even irrelevant video content targeting countries, leaders, ruling and opposition parties. In this case some countries are against them which has repeatedly blocked access to YouTube where Turkey is located. The first block in Turkey, was made because of the video uploaded to YouTube on March 3, 2007 containing insulting Mustafa Kemal Ataturk. The International Licensing Service, located in central Germany, removed access to the site on October 30, 2010 (Wikipedia, 2017) with the removal of relevant videos on the application to YouTube to buy and remove copyrighted videos that insult Ataturk.

In this study, Mehmet Ekin Vaiz's What Will Be Happen News Bulletin videos on YouTube are both for political aspect criticizing the political system and politicians in the North Cyprus, and the growing interest in video over time. These videos have two important characteristics of YouTube content can have it.

\section{METHOD}

\section{Conceptualization of Trolling and Troll Culture}

In the light of this information, the following research question is going to be tested:

RQ1: Did Mehmet Ekin Vaiz's 'What Will Be Happen News Bulletin' practice an application of 'trolling culture in political communication' during the North Cyprus 2015 Presidential Election?

The aim of this research is to examine how the Mehmet Ekin Vaiz's What Will Be Happen News Bulletin is accepted as an application of trolling behavior in North Cyprus political communication. The main subjects of interest are the 2015 Presidential Election in North Cyprus and political actors, matters of troll culture, representations about the candidates engaged in the election, position vis-à-vis the trolling. We sought answer to question related to the approaches and position the trolling and troll culture, and their views as these are expressed in videos, or that transpire between the lines as hidden or implied meanings. We are interested in features indicating trolling in social media more precisely YouTube.

The object of our study is mixed approach method between media content- analysis of online videos in combination with survey (Alexander, et al., 2008; Ciftci, 2014). We will accomplish this through an attempt to understand and analyze the practices implemented by Mehmet Ekin Vaiz What Will Be Happen News Bulletin in his selection and presentation of candidates and the concept of 'trolling' application. Observations and analysis are based solely on the actual material published on Mehmet Ekin Vaiz What Will Be Happen News Bulletin YouTube Channel. Moreover, the content is examined to derive its substance and implied meaning, which could enable us to anticipate or make 
corollaries as to its effects. Thus, our research is applied social media content analysis to a limited extent.

\section{Data Collection}

The majority of videos during the pre-election period consisted of short videos about the North Cyprus 2015 Presidential Election candidates and their campaigning strategies occupied on YouTube channel and also Facebook account of Mehmet Ekin Vaiz What Will Be Happen News Bulletin, which followed by majority of young generation.

In order to explore the videos about the North Cyprus 2015 Presidential Election and how What Will Be Happen News Bulletin covered the pre-election period, a content analysis coding schema has been developed. The content analysis coding schema has 10 variables related to the video contents: an evaluation of the troll; quoted candidates in the videos; the main topic of the videos; and some other technical information such as length of video, place, date and other variables. The samples selected for this study are $23(n=23)$ videos from YouTube channel of What Will Be Happen News Bulletin we selected the YouTube Channel and this specific program for a number of reasons. First, What Will Be Happen News Bulletin has the highest followers in the social media and the first and unique examples for the trolling behavior, is highly influential, and supports creative language culture.

\section{Descriptive Statistics}

A total of 23 YouTube videos, $(n=23)$ was collected. The mean length of the videos of the 23 news items was 8.33, $(S D=8.57)$, and was ranging from 4.43 to 12.55 minutes. The mean length of the videos disseminated in What Will Be Happen New Bulletin YouTube channel was significantly higher $(M=8.64, S D=8.90)$ before 2015 Presidential Election in North Cyprus, than in after election $(M=7.46, S D=6.49 ; t(23)=2.61, p<.001)$. The mean number of persons watched the videos was $1570,(S D=166.94)$, and was ranging from 532 to 15600 watchers. Videos directly published by What Will Be Happen New Bulletin YouTube channel was significantly more watched before 2015 Presidential Election in North Cyprus $(M=1.830, S D=207.88)$ than videos published after election $(M=833$, and $S D=.82 .05 ; t(23)=13.20, p<.001)$. The number of videos published by What Will Be Happen New Bulletin YouTube channel before election $(n=17)$ is higher than the number of videos published by What Will Be Happen New Bulletin YouTube channel after election, $(n=6)$ during the publication month between $22^{\text {nd }}$ March 2015 and $26^{\text {th }}$ of April.

\section{RESULTS}

The conception of social media shares play a role in informing environment not only for everyday issues but also for political issues. In this study, when videos were watched the application of trolling behavior in North Cyprus political communication, the majority of the video contents were in favor of the troll culture. Contrary to some speculations about trolling practices which suggested that most tended to create reaction and hatred issues (Hawkins, 2002), our results are suggested that Mehmet Ekin Vaiz What Will Be Happen News Bulletin considered his primary goal to be entertain public about the North Cyprus 2015 Presidential Election and its candidates.

Research question 1 (RQ1) was answered based on definition and characteristics of troll, trolling behavior and creative language culture. The 5 main characteristics are decided to use from the already existing literature (Bishop, 2014). These are as follows:

- Entertainment: The idea of classical trolling was mainly based on the entertainment, which is appeared in the social media Through this entertainment 
Online Journal of Communication and Media Technologies, 2018

Table 1. Candidates' election campaigns visits and favorite games

\begin{tabular}{lc}
\hline Candidates & Election campaigns visit 1 \\
\hline Mustafa Akıncı & Smurfs Village Visit \\
Derviş Eroğlu & The Lord of the Rings- Gandalf Visit \\
Sibel Siber & Hogwarts Visit \\
Kudret Özersay & Heidi Village Visit \\
\hline
\end{tabular}

process, people are communicating as well. Therefore, it is easy to say that trolling are serving the entertaining materials mostly by using social networks (Bishop, 2014).

- Creative Language and Visual Creativity: Trolls are made by creative language apparatuses, which are often visually developed.

- Humor: Trolling culture are not pleased to used bad language. Thus trolling behaviors use creative language and these creative language apply to use humor.

- Visibility: Although trolling is for entertainment, it is also played role in informing people for the public issues. Therefore, it is true to say that trolling activities helped public issues by making them visible via social networks (Taiwo, 2014).

- Legitimacy of political and cultural corruption: Trolling is legitimized the political and cultural corruption by presenting these issues humorously.

An overwhelming majority of videos (22 out of 23) showed that Mehmet Ekin Vaiz's "What Will Be Happen News Bulletin" conforms the notion of trolling culture. In each separate video he designed one scenario for each North Cyprus 2015 Presidential Election candidates; that it was the first time that Turkish Cypriot social media experienced troll culture.

In trolling culture, humor plays a key role in presenting the issues through social networks. In our sample, Mehmet Ekin Vaiz consistently uses humor. In terms of using humor in videos of "What Will Be Happen News Bulletin", he presented candidates election campaigns visits by referring the film characters and superheroes as explained in Table 1.

As illustrated in Table 1, Mehmet Ekin Vaiz used candidates' election campaign visits in his What Will Be Happen News Bulletin. By using both creative language and humor together, he artificially presented these visits. To begin with Mustafa Akinci, he preferred Smurfs Village. Then, he mentioned that Akinci and Papa Smurf will follow common act plan for Gargamel. For Eroğlu, Mehmet Ekin Vaiz selected to use Gandalff, who is the popular character of the film Lord of the Rings. Here, Mehmet Ekin Vaiz tried to highlight the candidate Eroğlu sensational statement of 'Kudret became a politician because of me'. Additionally, Hogwarts was used as an entertainment tool for mentioning the Sibel Siber election campaigns visit by Mehmet Ekin Vaiz. While all the candidates' election campaigns visits were with popular, strong characters, for Kudret Özersay's election campaign visit he picked Heidi Village. In this video, Mehmet Ekin Vaiz underlined the idea that Kudret Özersay was candidate for younger generation that if he is going to be selected, he will make a free internet connection for Heidi Village. The pictures (Figure 2) were illustrated the above mentioned information. 


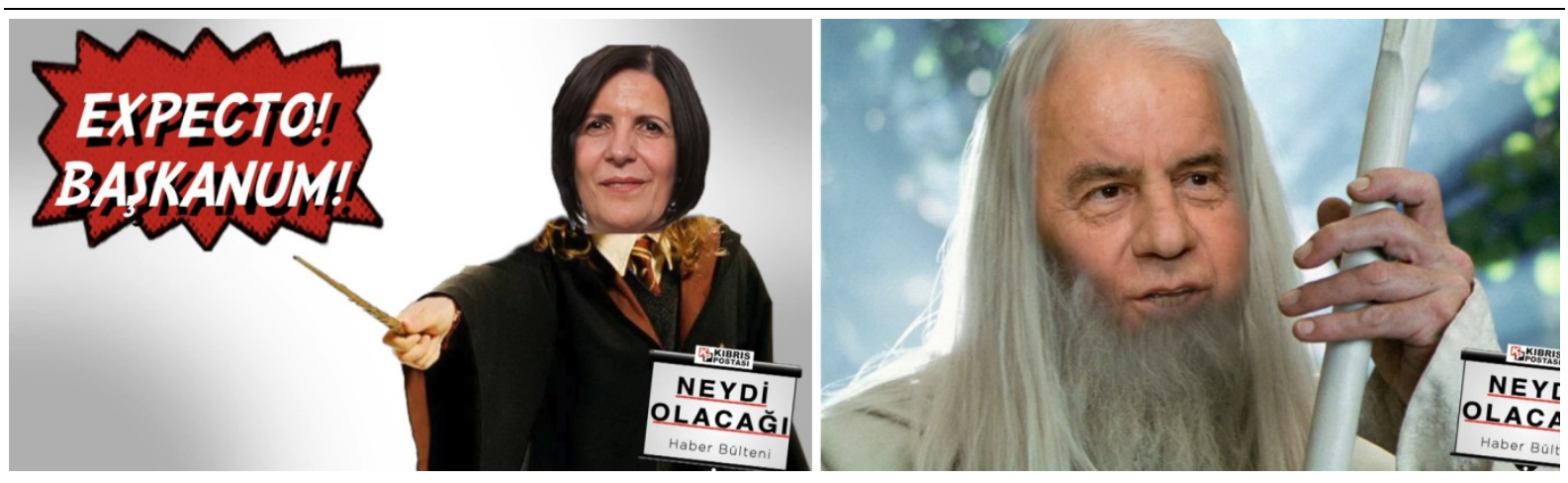

Figure 2. Sibel Siber (left side) and Dervis Eroglu (right side)

Table 2. Candidates' Favorite Games

\begin{tabular}{lc}
\hline Candidates & Candidates' favorite games \\
\hline Mustafa Akıncı & Angry Birds \\
Derviş Eroğlu & Crash of Clans \\
Sibel Siber & Hayday \\
Kudret Özersay & Fruit Ninja \\
\hline
\end{tabular}
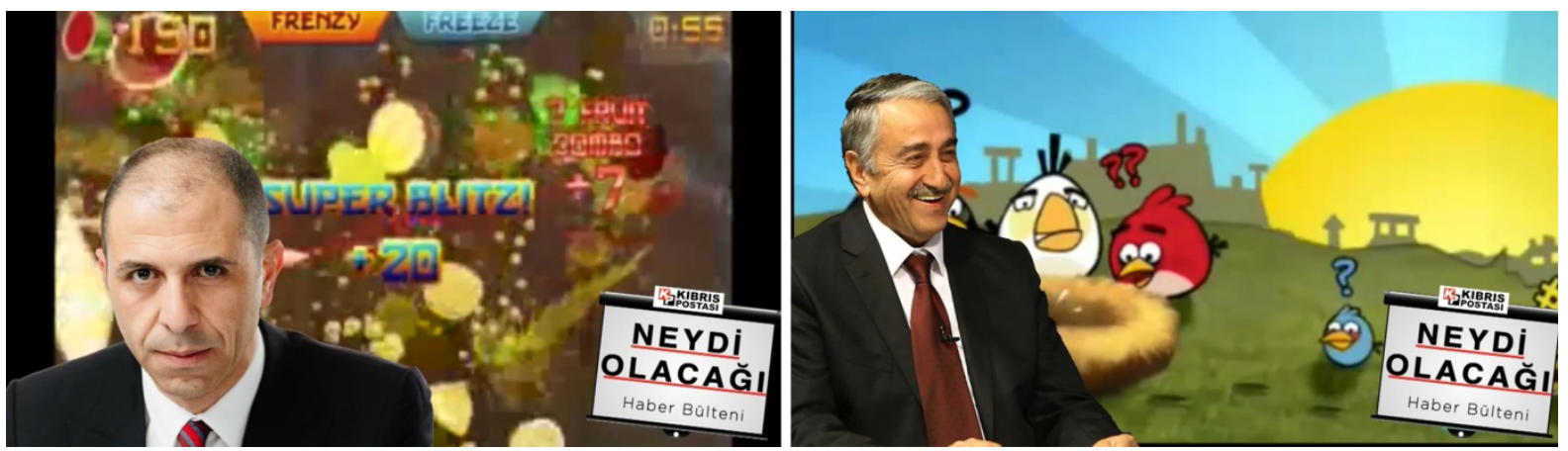

Figure 3. Kudret Özersay's (left side) and Mustafa Akıncı's (right side) Favorite Games

Table 2 was explored the candidates' favorite games. In What Will Be Happen News Bulletin, Mehmet Ekin Vaiz supported that candidates' favorite games were the most important sign to get know the candidates well. In the light of this statement, Mehmet Ekin Vaiz presented the candidates' favorite games in the videos. For Mustafa Akıncı, he picked Angry Birds, since his party logo was a bird which was represented 'peace' in the Cyprus context. On the other hand, Mehmet Ekin Vaiz pointed out that, Derviş Eroğlu as North Cyprus 2015 Presidential Election candidate plays Crash of Clans game, which is included mostly war and conquer simulations. In other words, Mehmet Ekin Vaiz favored to use this game for him, since Eroğlu and his party was representing nationalist ideologies. Furthermore, Hayday was the favorite game for the candidate Sibel Siber, which has got farm simulations. Finally, Kudret Özersay's favorite game was Fruit Ninja, which was known as adventure game. All this favorite games and candidates were matched through candidates' personality and presented to public for entertainment. Please see the Figure 3 for the illustration.

On the other hand, using a creative language apparatuses are another important practices of trolling, which Mehmet Ekin Vaiz used a lot in the videos. As Table 3 shows that all statements are not only composed creative language but also produced visual creativity. For Mustafa Akıncı, he wanted to recall the idea that Akıncı was lived in USA for ten years before the North Cyprus 2015 Presidential Election. Therefore, he created the statement by making fun of already existing debates of Akıncı last residential issue. 
Online Journal of Communication and Media Technologies, 2018

Table 3. Candidates' Latters for Tsipras (Prime Minister of Greece)

\begin{tabular}{lc}
\hline Candidates & Letters for Tsipras (Prime Minister of Greece) \\
\hline Mustafa Akinci & "If I won't be elected, I will come Greece instead of USA" \\
Dervis Eroglu & "Do we have more officers than the Soviets" \\
Sibel Siber & "You know I am communits, progress, change, transformation and conjecture" \\
Kudret Ozersay & "Have we not play Atari in the same period?" \\
\hline
\end{tabular}

Table 4. Percentage of Citizen Perception on Troll Culture Characteristics of What Will Be Happen News Bulletin

\begin{tabular}{lccc}
\hline Troll culture characteristics & Yes (\%) & No (\%) & Don't mention (\%) \\
\hline Political & 91.3 & 11.7 & - \\
Entertainment \& Humor & 46.7 & 53.3 & - \\
Political Opponent & 34 & 27.7 & 38.3 \\
\hline
\end{tabular}

In addition to that, the main discussion for Derviş Eroğlu was the high number of officers in North Cyprus. Thus, after Tsipras has visited Russia, Mehmet Ekin Vaiz in his scenario of letters for Tsipras used this critical point of North Cyprus political communication in the video. Similar with other candidates, the debates of Sibel Siber nomination was based on her election campaign slogan, which is progress, change, transformation and conjecture. Mehmet Ekin Vaiz in his news bulletin video exacerbating this issue by making statement of 'You know I am communists, progress, change, transformation and conjecture'. Moreover, for Kudret Özersay's nomination main debate was based on the idea that he has been negotiator for twelve years, as Mehmet Ekin Vaiz used this in the video by saying that 'we were playing Atari same period.

For visibility, political corruption and political decay, Mehmet Ekin Vaiz in his What Will Be Happen News Bulletin created a video. In this video he used some visual creativity as well as creative language. For example, he made a video from one German Parliament debate, which includes unrelated Turkish subtitles. It is clear from the subtitles that all the North Cyprus 2015 Presidential election candidates were asked to get money from the German Parliament member. From this example, it is true to say that Mehmet Ekin Vaiz tried to make the biggest social problems of funding from the external bodies during the election periods. Similarly, another video mainly based on the interview with the citizens, which Mehmet Ekin Vaiz was called as "Opponent Citizen". In this interview video, citizens apparently talked about the bribery, that all the candidates were appealed bribery. Therefore, in the end of the video it is said that opponent citizens are going to wait until the last minute of election for bribe.

A survey was conducted by $100(n=100)$ citizens, who live $7(n=7)$ different cities [i.e. Karpaz, İskele, Lefke, Güzelyurt, Girne, Gazimağusa and Lefkoşa]. A majority of total answers came from the city of Lefkoşa (\%72), since Lefkoşa is the capital of North Cyprus and it is also most crowded city of the island. The majority of the participants were belong to young generation [i.e. between 18 to 30] who have right to vote in North Cyprus 2015 Presidential election (\%62). Significantly, in North Cyprus \%88 voters follow internet to be aware of the political issues. Thus the survey results proved that internet would be accepted as a first tool for young Turkish Cypriots. Similarly, the survey results showed that the majority of the participants (\%72) watched What Will Be Happen News Bulletin before the North Cyprus 2015 Presidential Election. On the other hand, Table 4 illustrates the percentage of survey participants perceptions' on troll culture characteristics of What Will Be Happen News Bulletin as discussed in the previous parts of this study. 


\section{DISCUSSION AND CONCLUSION}

The purpose of this study was to provide a first and preliminary insight into troll culture in North Cyprus during the pre-election and post-election period of the North Cyprus 2015 Presidential Election. A content-analysis on the troll culture with a combination of survey results provided a rich collection of data analysis. The survey results were analyzed within the context of the findings of video content-analysis focusing mostly on the characteristics of troll culture and application of trolling behavior in North Cyprus political communication.

North Cyprus plays a special case for trolling that traditional media system had not yet evolved in professional level, although the majority of the population are familiar and also became user of the social media. Participants of this study found that videos on the YouTube channel of Mehmet Ekin Vaiz have included political content however they were represented in a humor-based way. In the light of this information, the example of What Will Be Happen News Bulletin is accepted as classical trolling behavior based in the Bishop (2014) classification of two different trolling behaviuors. Moreover, by looking Taiwo (2014) categorization for troll culture, it can be true to say that the data that are used in this study might be an example of using creative culture practices for criticizing the social problems on social networks as well.

We were interested in whether the prevalence of creative culture and trolling behavior affect the voters' decision on North Cyprus 2015 Presidential Election. Our survey results suggest that trustworthiness of the politicians more important than the creative culture, which the participants were not trusted political discourse either in traditional media or new media, which is YouTube in our study, apparatuses in North Cyprus.

In this research the role of trolling culture through Mehmet Ekin Vaiz's What Will Be Happen News Bulletin was discussed on the interest in new media apparatuses and the role of the creative culture. Besides, we need to signify that political interest plays central role in this relations between the trolling behavior and political communication. With the use of existing videos on YouTube and by conducting small online survey it is seemed to be crucial that this Mehmet Ekin Vaiz's were the first one who producing creative culture in North Cyprus through the social networks and his news bulletin is the first example of the application of trolling behavior in North Cyprus political communication.

\section{REFERENCES}

Aktas, O. (2016). Caps/Memes as a Communication Method. Inonu University Journal of Arts and Design, 6(14), 1-14. Retrieved from http://dergipark.gov.tr/download/articlefile/317846

Alexander, V. D., Thomas, H., Cronin, A., Fielding, J., \& Moran-Ellis, J. (2008). Mixed methods. In N. Gilbert \& P. Stoneman (Eds.), Researching Social Life (pp. 22-42). London: Sage Publication.

Ayvaz, T. (2016, January 29). İnternet ve Sosyal Medya Kullanıcı İstatistikleri 2016 [in Turkish]. Dijital Ajanslar. Retrieved from http://www.dijitalajanslar.com/internetve-sosyal-medya-kullanici-istatistikleri-2016/

Binark, M., \& Loker, K. (2011). Sivil Toplum Örgütleri Iç̧in Bilişim Rehberi [in Turkish]. Ankara: Civil Society Development Center.

Binark, M., Karatas, S., Comu, T., \& Koca, E. (2015). Türkiye'de Twitter'da Trol Kültürü [in Turkish]. Toplum ve Bilim Dergisi, 135, 124-157. 
Bishop, J. (2014). Dealing with Internet Trolling in Political Online Communications: Towards the This is Why We Can't Have Nice Things Scale. International Journal of E-Politics, 5(4), 1-20. Retrieved from https://dl.acm.org/citation.cfm?id=2720815 https://doi.org/10.4018/ijep.2014100101

Chang, Y. F., \& Chen, C. S. (2005). Smart Phone - The Choice of Client Platform for Mobile Commerce. Computer Standards \& Interfaces, 27(4), 329-336. https://doi.org/10.1016/j.csi.2004.10.001

Chen, C.-W., Chang, H.-Y., Chen, J.-H., \& Weng, R. (2016). Elucidating the Role of Conformity in Innovative Smartphones. International Journal of Mobile Communications, 14(1), 56-78. https://doi.org/10.1504/IJMC.2016.073367

Ciftci, D. (2014). Peace Journalism and News Coverage on the Annan Plan Referendum: The Role of Framing the Conflict Issues and Negotiation Process. GSTF Journal on Media \& Communications (JMC), 1(2), 46-59. https://doi.org/10.5176/23356618_1.2.19

Coleman, E. G. (2012). Phreaks, Hackers and Trolls. The Politics of Transgression and Spectacle. In M. Mandiberg (Eds.), The Social Media Reader (pp. 99-119). New York: New York University Press.

Geray, H. (2003). İletişim ve Teknoloji; Uluslararası Birikim Düzeyinde Yeni Medya Politikaları [in Turkish]. Ankara: Utopya.

Goffman, E. (2014). The Presentation of Self Everyday Life. Istanbul: Metis.

Goncharova, M. (2012). Planet Play: Designing a Game for Children to Promote Environmental Awareness. Online Journal of Communication and Media Technologies, 2(4), 137-154.

Halder, I., Halder, S., \& Guha, A. (2015). Education Use of Mobile Phones by Undergraduate Students: An Indian Perspective. . Online Journal of Communication and Media Technologies, 5(4), 64-76.

Hardaker, C. (2013). Uh.... Not to be Nitpicky, but... the Past Tense of Drag is Dragged, not Drug. Journal of Language Aggression and Conflict, 1(1), 58-86. Retrieved on 1 April 2018 from http://www.academia.edu/3061027/_Uh....not_to_be_nitpicky_but... the_past_tense_of_drag_is_dragged_not_drug._An_overview_of_trolling_strategies https://doi.org/10.1075/jlac.1.1.04har

Karatas, S., \& Binark, M. (2016). Creative Culture in New Media: Twitter Trolls and "Caps" Creativity. TRT Akademi, 1(2), 426-448.

Kim, H., Lee, D., \& Hwang, J. (2016). Measuring the Efficiency of Standardisation Policy Using Meta-Frontier Analysis: A Case of Mobile Platform Standardisation. International Journal of Mobile Communications, 14(1), 79-98. https://doi.org/10.1504/IJMC.2016.073368

Lister, M., Giddens, S., \& Dovey, J. (2009). New Media: A Critical Introduction. New York: Routledge.

Martin, J. A. (2016). Mobile Media Activity Breadth and Political Engagement: An Online Resource Perspective. International Journal of Mobile Communications, 14(1), 2642. https://doi.org/10.1504/IJMC.2016.073354

Meikle, G. (2016). Social Media: Communication, Sharing and Visibility. London: Routledge. https://doi.org/10.4324/9781315884172

Ozinanir, C. I. (2009). Antikapitalist Hareket ve Yeni Iletişim Teknolojileri (Graduate thesis) [in Turkish], Ankara: Ankara University. 
Ozok, A. A., \& Wei, J. (2010). An Empirical Comparison of Consumer Usability Preferences in Online Shopping Using Stationary and Mobile Devices: Results from a College Student Population. Electronic Commerce Research, 10(2), 111-137. https://doi.org/10.1007/s10660-010-9048-y

Ozsoy, D. (2015). Tweeting Political Fear: Trolls in Turkey. Journal of History School, 12, 535-552. Retrieved from www.johschool.com/DergiPdfDetay.aspx?ID=750 https://doi.org/10.14225/Joh750

Park, C. S. (2017). Unpacking the Relationship between Mobile Phone Usage Patterns, Networks Size, and Civic Engagement. Online Journal of Communication and Media Technologies, 7(2), 169-197.

Rogers, E. (1995). Diffusion of Innovations. New York: The Free Press.

Silverstone, R. (1999). What's New about New Media. New Media \& Society, 1(1), 10-82. Available at: http://journals.sagepub.com/doi/abs/10.1177/1461444899001001002

Straubhaar, J., LaRose, R., \& Davenport, L. (2011). Media Now: Understanding Media, Culture and Technology. Wadsworth: Cengage Learning.

Suh, Y., Lee, H., \& Park, Y. (2012). Analysis and Visualisation of Structure of Smartphone Application Services Using Text Mining and the Set-Covering Algorithm: A Case of App Store. International Journal of Mobile Communications, 10(1), 1-20. https://doi.org/10.1504/IJMC.2012.044520

Taiwo, R. (2014). Impoliteness in Online Forums: A Study of Trolling in Nairaland. In I. Chiluwa, P.A. Ifukor and R. Taiwo (Eds.), Pragmatics of Nigerian English in Digital Discourse (pp. 67-76). Munich: Lincom Europa.

Torenli, N. (2005). Yeni Medya, Yeni İletişim Ortamı [in Turkish]. Ankara: Bilim ve Sanat Yayınları.

Tossell, C. C., Kortum, P., Shepard, C., Barg-Walkow, L. H., Rahmati, A., \& Zhong, L. (2012), A Longitudinal Study of Emoticon Use in Text Messaging From Smartphones. Computers in Human Behavior, 28(2), 659-663. https://doi.org/10.1016/j.chb.2011.11.012

Wikipedia (2018, March 30). YouTube'a Türkiye'den Erişimin Engellenmesi [in Turkish]. Retrieved from https://tr.wikipedia.org/wiki/YouTube\%27a_Türkiye\%27den_ erişimin_engellenmesi

Woog, A. (2008). A Great Idea: YouTube. Chicago: Norwood House Press.

Ziani, A., Elareshi, M., \& Alrashid, M. (2018). Exploring Arab Media Group's Motivations for Using Facebook. Online Journal of Communication and Media Technologies, 8(1), 88-111.

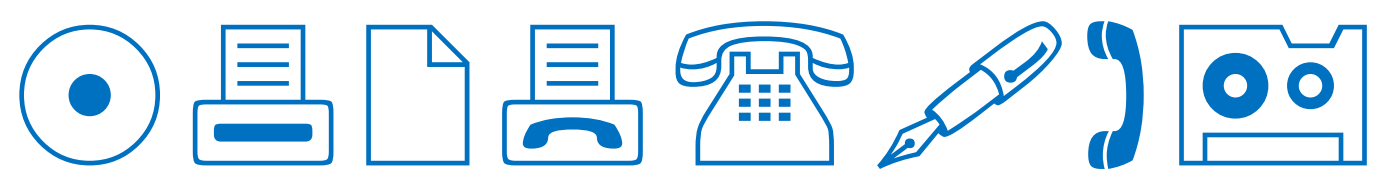

